\title{
The influence of a long-term growth hormone treatment on lipid and glucose metabolism: a randomized trial in short Japanese children born small for gestational age
}

\author{
Reiko Horikawa ${ }^{1 *}$, Toshiaki Tanaka², Hiromi Nishinaga ${ }^{3}$, Yoshihisa Ogawa ${ }^{3}$ and Susumu Yokoya ${ }^{4}$
}

\begin{abstract}
Background: Long-term growth hormone $(\mathrm{GH})$ treatments in short children born small for gestational age (SGA) restore lipid metabolism, but also increase insulin resistance. The aim of this study was to evaluate the influence of long-term GH therapy on lipid and glucose metabolism as well as its dose dependency in short Japanese children born SGA.
\end{abstract}

Methods: Eighty Japanese children with a short stature who were born SGA participated in this study; 65 were treated with fixed GH doses of 0.033 (low) or 0.067 (high) mg/kg/day for 260 weeks; 15 were untreated controls in the first year and were randomized to one of the two treatment groups at week 52. Serum cholesterol, glucose and insulin levels were regularly measured. An oral glucose tolerance test (OGT) was conducted annually.

Results: The mean age at the start of GH therapy was approximately 5.3 years. Serum total cholesterol (TC) and low-density lipoprotein cholesterol (LDL-C) in the high dose group significantly decreased over time during $\mathrm{GH}$ therapy. In both dose groups for TC, and in the high dose group for LDL-C, the higher the baseline values, the greater the decrease after 260 weeks. The rate of the decrease observed after 260 weeks in patients with high LDL-C levels was greater in the high dose group. Based on the results of OGTT, no patient was classified as being diabetic; however, annual increases were observed in post-OGTT insulin levels. After 260 weeks, the homeostasis model assessment as an index of insulin resistance (HOMA-IR) increased, suggesting that insulin resistance developed over time with the $\mathrm{GH}$ treatment, while $36.6 \%$ of the subjects entered puberty.

Conclusions: Long-term continuous GH treatment for children born SGA may have a potentially beneficial effect on several parameters in lipid metabolism and does not adversely affect glucose metabolism.

Trial registration: GHLIQUID-1516, GHLIQUID-1517, Japan Pharmaceutical Information Center Clinical trial registration: JapicCTI-050132. Registered 13 September 2005. Retrospectively registered. JapicCTI-050137. Registered 13 September 2005. Retrospectively registered. ClinicalTrials.gov trial registration: NCT00184717. Registered 13 September 2005. Retrospectively registered.

Keywords: Growth hormone, GH therapy, Small for gestational age, Short stature, Norditropin ${ }^{\oplus}$, Japanese, Lipid metabolism, Glucose metabolism, Insulin resistance

\footnotetext{
*Correspondence: horikawa-r@ncchd.go.jp

${ }^{1}$ Division of Endocrinology and Metabolism, National Center for Child Health

and Development, 2-10-1 Okura, Setagaya-ku, Tokyo 157-8535, Japan

Full list of author information is available at the end of the article
} 


\section{Background}

Small for gestational age (SGA) is defined as birth weight and length below the 10th percentile for gestational age in Japan [1]. Approximately $10 \%$ of children born SGA will not achieve catch-up growth by 2 years of age, and will remain short throughout their lives if left untreated [2-4].

A previous study reported that low birth weight was associated with the development of type 2 diabetes mellitus, hypertension, and hyperlipidemia in adulthood [5]. Furthermore, rapid catch-up in the weight of these children has been suggested to increase the risk of various medical conditions $[6,7]$.

The mechanisms underlying these risks have been examined, with increases in insulin resistance and/or intra-abdominal fat being implicated in this phenomenon [8]. Increases in insulin resistance may cause impairments in the growth hormone (GH)-insulin-like growth factor (IGF)-binding protein axis or be a consequence of these impairments [9].

$\mathrm{GH}$ treatments have been approved for the treatment of children with short stature born SGA without spontaneous catch-up growth. GH therapy has been suggested to provide additional, long-term metabolic benefits, thereby mitigating the metabolic consequences of being born SGA, while still facilitating early ageappropriate catch-up growth [10]. On the other hand, $\mathrm{GH}$ treatments have been reported to increase insulin resistance with the over-secretion of insulin occurring to compensate.

This was a 260 week (5 year) clinical study investigating the effect of long-term GH therapy in Japanese patients with SGA-related short stature. Height efficacy and safety data [11] and the beneficial effects on metabolic parameters (glucose, insulin, total cholesterol [TC], low-density lipoprotein cholesterol [LDL-C], highdensity lipoprotein cholesterol [HDL-C]) [12] in these patients have been reported previously. In the present analysis, we examined the relationship between baseline status and changes of lipid metabolism-associated parameters after long-term (260 weeks) GH therapy, in addition to effects on other metabolic parameters including glycated hemoglobin $\mathrm{A}_{1 \mathrm{c}}\left(\mathrm{HbA}_{1 \mathrm{c}}\right)$, blood glucose and insulin levels before and after an oral glucose tolerance test (OGTT), homeostasis model assessment as an index of insulin resistance (HOMA-IR), and insulinogenic index.

\section{Methods}

\section{Patients}

The study population comprised 80 short children born SGA, aged 3-8 years, who were randomly assigned to two groups receiving a low or high dose (0.033 or $0.067 \mathrm{mg} / \mathrm{kg} /$ day $)$ of $\mathrm{GH}(n=31$ and 34 , respectively). A control group (no treatment, $n=15$ ) was established during the first 52 weeks (1 year) and compared with the $\mathrm{GH}$ therapy groups. Patients from the control group were randomized to one of the treatment groups at week 52. Further details concerning inclusion and exclusion criteria have been described previously [11].

\section{Study preparations}

Packaging of trial products were indistinguishable from one another and the doctors and the patients were blinded to their group allocation. Both $\mathrm{GH}$ doses were injected using a GH injection device (NordiPen $^{\oplus} 5$ and PenNeedle; ${ }^{\oplus}$ Novo Nordisk A/S) to maintain blinding.

\section{Study design}

This study involved a 156-week extension of a 104week (260 weeks in total) multicenter, randomized, double-blind, parallel-group trial investigating the efficacy and safety of two doses of GH. In patients assigned to receive long-term GH therapy, GH was subcutaneously injected daily before bedtime. In those assigned to the control group (52 weeks), follow-up alone was performed without $\mathrm{GH}$. The trial was performed between July 2003 and December 2009. Patient visits were planned at 13 -week intervals with a \pm 14 -day window, and 15 visits were scheduled over the course of the 260-week trial.

Metabolic parameters assessed included: TC, LDL-C, HDL-C, $\mathrm{HbA}_{1 \mathrm{c}}$, blood glucose and insulin levels before and after an OGTT, HOMA-IR, and insulinogenic index ( $\Delta$ insulin 0-30 $\mathrm{min} / \Delta$ glucose $0-30 \mathrm{~min}$ ).

On the basis of the results of OGTT $(1.75 \mathrm{~g} / \mathrm{kg}$, maximum $75 \mathrm{~g}$ ), individual patients were classified into three types: normal, glucose intolerant, and diabetic, according to the criteria for hyperglycemia established by the Japan Diabetes Society [13, 14]. Patients were categorized as glucose intolerant if they had a fasting blood glucose level of $110-125 \mathrm{mg} / \mathrm{dL}$ and/or a value of $140-199 \mathrm{mg} / \mathrm{dL}$ at $120 \mathrm{~min}$ after OGTT, or a blood glucose level of $180 \mathrm{mg} / \mathrm{dL}$ or more $60 \mathrm{~min}$ after OGTT. Changes in body weight and body mass index (BMI) SDS were also reported.

\section{Statistical analysis}

Summary statistics (mean with SD) were calculated for baseline patient demographics. A closed testing procedure was applied for analyses at 52 weeks since two hypotheses (low or high dose group vs. no treatment group) were tested at 52 weeks. Changes from baseline for the parameters of lipid metabolism were analyzed using a 2 -sided $t$-test based on $\mathrm{t}$-distribution for each treatment group. A significance level of $5 \%$ was 
used, and confidence intervals (CI) were constructed with a confidence coefficient of $95 \%$. Simple correlation analysis was used to evaluate the relationship between baseline and change in the parameters of lipid metabolism, between HOMA-IR and BMI SDS at 260 weeks, and between $\mathrm{HbA}_{1 \mathrm{c}}$ and BMI SDS at 260 weeks.

\section{Results}

\section{Patient demographics}

Baseline patient demographics are outlined in Tables 1 and 2. No significant differences were observed in patient backgrounds at baseline among the three groups; however, the proportion of boys was higher in the low and high dose groups than in the no treatment group. At treatment start, the mean age, height SDS, and IGF-I SDS were approximately 5.3 years, -3.0 , and -0.7 , respectively.

\section{Influence on lipid metabolism}

We analyzed lipid parameters at the start of GH therapy and after 260 weeks. In the low dose group, no significant differences were noted in the mean TC and LDL-C levels between the two time points (Fig. 1a and b, respectively). In the high dose group, a significant decrease was observed after 260 weeks $(p<0.0005$ and $p<0.0001$, respectively). In the low dose group, the mean HDL$C$ level after 260 weeks was significantly higher than at the start of GH therapy $(p<0.05$, Fig. $1 \mathrm{c})$, whereas no significant difference was found in the high dose group.

Correlations between the baseline values and changes from baseline to 260 weeks in TC, LDL-C, and HDL-C levels are shown in Fig. 2. Changes in TC levels were negatively correlated with baseline values in the two dose groups (Fig. 2a). A similar correlation was observed between LDL-C levels at the start of GH therapy and the change noted after 260 weeks (Fig. 2b). This correlation was particularly strong in the high dose group. No correlation was detected between HDL-C levels at the start of GH therapy and the change noted after 260 weeks in either group (Fig. 2c).

\section{Influence on glucose metabolism}

In the two dose groups, $\mathrm{HbA}_{1 \mathrm{c}}$ (National Glycohemoglobin Standardization Program [NGSP]) values increased until 104 weeks after the start of GH therapy, and remained constant thereafter (Fig. 3). In the low and high dose groups, the mean $\mathrm{HbA}_{1 \mathrm{c}}$ values at 260 weeks after the start of GH therapy were 5.29 and $5.33 \%$, respectively, which were within the normal range (4.6$6.2 \%)$. Furthermore, no patient showed an $\mathrm{HbA}_{1 \mathrm{c}}$ value beyond the standard value range during the study period (260 weeks).

No marked changes were noted in the blood glucose response to OGTT during 260 weeks of the treatment in either group (Fig. 4). Regarding the influence of long-term GH therapy on insulin levels after OGTT, the peak value in the high dose group

Table 1 Patient demographics [Mean \pm SD]

\begin{tabular}{|c|c|c|c|c|c|c|}
\hline & No treatment & & $0.033 \mathrm{mg} / \mathrm{kg} / \mathrm{day}$ & & $0.067 \mathrm{mg} / \mathrm{kg} / \mathrm{day}$ & \\
\hline & & $n$ & & $n$ & & $\mathrm{n}$ \\
\hline Gender & & 15 & & 31 & & 34 \\
\hline Male, \% & 46.7 & 7 & 64.5 & 20 & 58.8 & 20 \\
\hline Female, \% & 53.3 & 8 & 35.5 & 11 & 41.2 & 14 \\
\hline Chronological age, years & $5.32 \pm 1.38$ & 15 & $5.34 \pm 1.46$ & 31 & $5.27 \pm 1.15$ & 34 \\
\hline Height, cm & $94.6 \pm 8.6$ & 15 & $95.9 \pm 8.4$ & 31 & $94.9 \pm 7.3$ & 34 \\
\hline Height SDS & $-2.92 \pm 0.53$ & 15 & $-2.95 \pm 0.64$ & 31 & $-2.90 \pm 0.67$ & 34 \\
\hline BMI & $14.07 \pm 1.40$ & 15 & $14.42 \pm 1.26$ & 31 & $14.16 \pm 1.24$ & 34 \\
\hline$|G F-|, n g / m L$ & $115.39 \pm 51.01$ & 15 & $117.25 \pm 49.13$ & 31 & $118.20 \pm 49.10$ & 34 \\
\hline IGF-I SDS & $-1.03 \pm 1.50$ & 15 & $-0.75 \pm 1.06$ & 31 & $-0.63 \pm 1.21$ & 34 \\
\hline Insulin, $\mu \mathrm{U} / \mathrm{mL}$ & $2.6 \pm 1.7$ & 10 & $3.6 \pm 2.1$ & 26 & $3.2 \pm 1.9$ & 28 \\
\hline Glucose, mg/dL & $79.8 \pm 6.3$ & 15 & $82.4 \pm 10.4$ & 31 & $78.2 \pm 11.5$ & 34 \\
\hline $\mathrm{HbA}_{1 \mathrm{c}}$ (NGSP), \% & $5.08 \pm 0.32$ & 15 & $5.10 \pm 0.29$ & 31 & $5.00 \pm 0.19$ & 34 \\
\hline $\mathrm{TC}, \mathrm{mg} / \mathrm{dL}$ & $173.5 \pm 24.2$ & 15 & $166.9 \pm 29.8$ & 31 & $181.4 \pm 24.2$ & 34 \\
\hline $\mathrm{LDL}-\mathrm{C}, \mathrm{mg} / \mathrm{dL}$ & $96.7 \pm 18.9$ & 15 & $94.8 \pm 26.2$ & 31 & $104.7 \pm 25.0$ & 34 \\
\hline $\mathrm{HDL}-\mathrm{C}, \mathrm{mg} / \mathrm{dL}$ & $60.4 \pm 15.9$ & 15 & $56.9 \pm 9.6$ & 31 & $61.9 \pm 12.0$ & 34 \\
\hline
\end{tabular}

$S D$ standard deviation, $S D S$ standard deviation score, $B M I$ body mass index, IGF-I insulin-like growth factor-1, $H b A_{1 c}$ glycated hemoglobin A1c, NGSP National Glycohemoglobin Standardization Program, TC total cholesterol, LDL-C low-density lipoprotein cholesterol, $H D L-C$ high-density lipoprotein cholesterol 
Table 2 Patient numbers evaluated as being the glucose intolerant type of diabetes mellitus [n (\%)]

\begin{tabular}{|c|c|c|c|c|c|c|c|c|c|c|}
\hline & \multicolumn{5}{|c|}{$0.033 \mathrm{mg} / \mathrm{kg} / \mathrm{day}$} & \multicolumn{5}{|c|}{$0.067 \mathrm{mg} / \mathrm{kg} / \mathrm{day}$} \\
\hline & \multirow[t]{2}{*}{ Total } & \multirow{2}{*}{$\begin{array}{l}\text { Glucose } \\
\text { intolerant } \\
\text { type }\end{array}$} & \multicolumn{3}{|c|}{$\begin{array}{l}\text { Time point evaluated as the glucose } \\
\text { intolerant type }\end{array}$} & \multirow[t]{2}{*}{ Total } & \multirow{2}{*}{$\begin{array}{l}\text { Glucose } \\
\text { intolerant } \\
\text { type }\end{array}$} & \multicolumn{3}{|c|}{$\begin{array}{l}\text { Time point evaluated as the glucose } \\
\text { intolerant type }\end{array}$} \\
\hline & & & Before & $60 \min ^{a}$ & $120 \mathrm{~min}$ & & & Before & $60 \min ^{*}$ & $120 \mathrm{~min}$ \\
\hline Baseline & 31 (100 \%) & $3(9.7 \%)$ & 1 (3.2 \%) & $0(0.0 \%)$ & $2(6.5 \%)$ & 34 (100\%) & 1 (2.9\%) & 0 (0.0\%) & $0(0.0 \%)$ & 1 (2.9\%) \\
\hline 52 weeks & 29 (100\%) & $3(10.3 \%)$ & 0 (0.0\%) & $2(6.9 \%)$ & 1 (3.4 \%) & $34(100 \%)$ & 3 (8.8 \%) & $0(0.0 \%)$ & $3(8.8 \%)$ & $0(0.0 \%)$ \\
\hline 104 weeks & 29 (100\%) & 2 (6.9\%) & $0(0.0 \%)$ & $0(0.0 \%)$ & 2 (6.9 \%) & 32 (100 \%) & 2 (6.3 \%) & $0(0.0 \%)$ & 0 (0.0\%) & 2 (6.3 \%) \\
\hline 156 weeks & $25(100 \%)$ & 1 (4.0\%) & $0(0.0 \%)$ & $0(0.0 \%)$ & 1 (4.0\%) & $29(100 \%)$ & 2 (6.9\%) & $0(0.0 \%)$ & $0(0.0 \%)$ & 2 (6.9\%) \\
\hline 208 weeks & 25 (100\%) & $0(0.0 \%)$ & $0(0.0 \%)$ & $0(0.0 \%)$ & 0 (0.0 \%) & 28 (100\%) & $3(10.7 \%)$ & $0(0.0 \%)$ & 2 (7.1\%) & $1(3.6 \%)$ \\
\hline 260 weeks & 23 (100 \%) & 1 (4.3\%) & 1 (4.3\%) & $0(0.0 \%)$ & 0 (0.0 \%) & 27 (100 \%) & 4 (14.8\%) & 0 (0.0\%) & 1 (3.7 \%) & $3(11.1 \%)$ \\
\hline
\end{tabular}

aPatients with a blood glucose level of $180 \mathrm{mg} / \mathrm{dL}$ or more $60 \mathrm{~min}$ after OGT were regarded as being glucose intolerant [14]. OGT, oral glucose tolerance test

was slightly higher than that in the low dose group (Fig. 5).

Although no marked changes were observed in fasting blood glucose levels, $\mathrm{HbA}_{1 \mathrm{c}}$ values slightly increased from 5.10 to $5.29 \%$ and from 5.00 to $5.33 \%$ in the low and high dose groups, respectively. Two patients were classified as being glucose intolerant based on fasting blood glucose levels. GH therapy had not been administered to one of these patients. In the low and high dose groups, 95.7 and $85.2 \%$ of patients were classified as being normal 260 weeks after the start of GH therapy, respectively. No patients were classified as being diabetic at any observation point.

An increase was noted in the mean HOMA-IR 260 weeks after the start of GH therapy (Table 3). However, no significant difference was noted in this increase that was related to the dose administered. Twenty-two patients (36.6\%) entered puberty during the study period (7 [35 \%] in the low dose group and 15 [37.5\%] in the high dose group).

No correlations were found between the HOMAIR and BMI SDS or between the $\mathrm{HbA}_{1 \mathrm{c}}$ and $\mathrm{BMI}$ SDS after 260 weeks of GH therapy (data not shown).

After 260 weeks of GH therapy, the insulinogenic index increased from 0.45 to 1.31 and 0.52 to 1.24 in the low and high dose groups, respectively; however, no dose-related differences were observed.

\section{Withdrawals}

Two patients discontinued treatment and withdrew from the study. One patient from the $0.033 \mathrm{mg} / \mathrm{kg} /$ day group withdrew after 151 weeks due to IgA nephropathy. The event was classed as a serious adverse
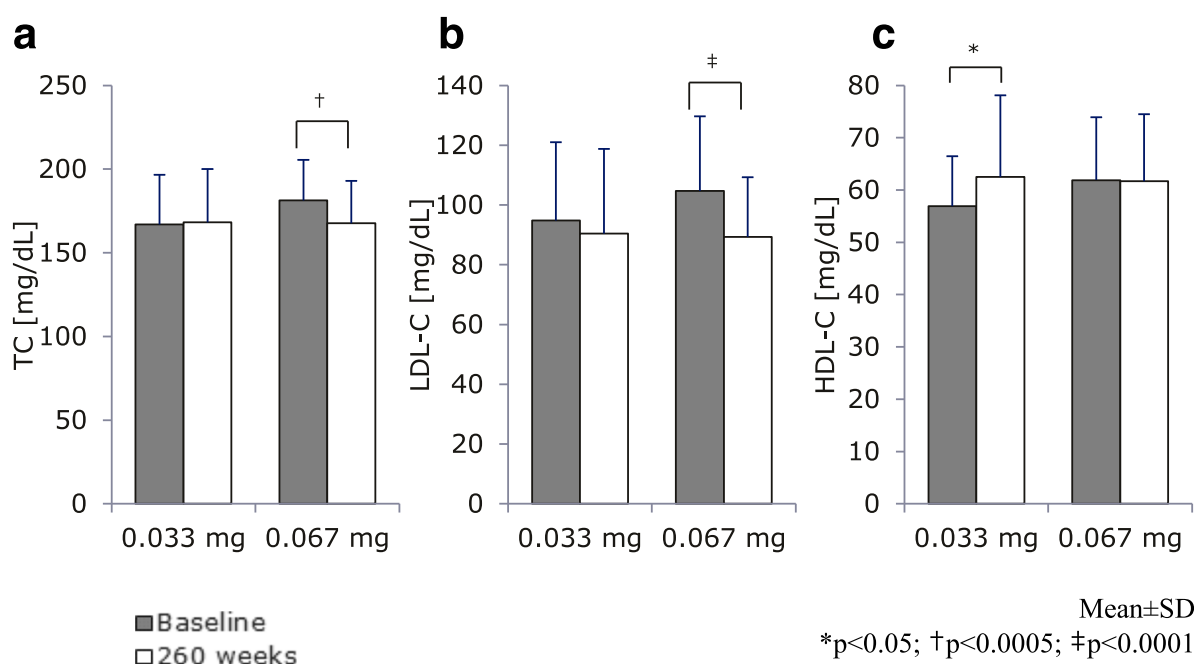

Fig. 1 (a) TC, (b) LDL-C, and (c) HDL-C values at baseline and week 260. TC, total cholesterol; LDL-C, low-density lipoprotein cholesterol; HDL-C, high-density lipoprotein cholesterol 


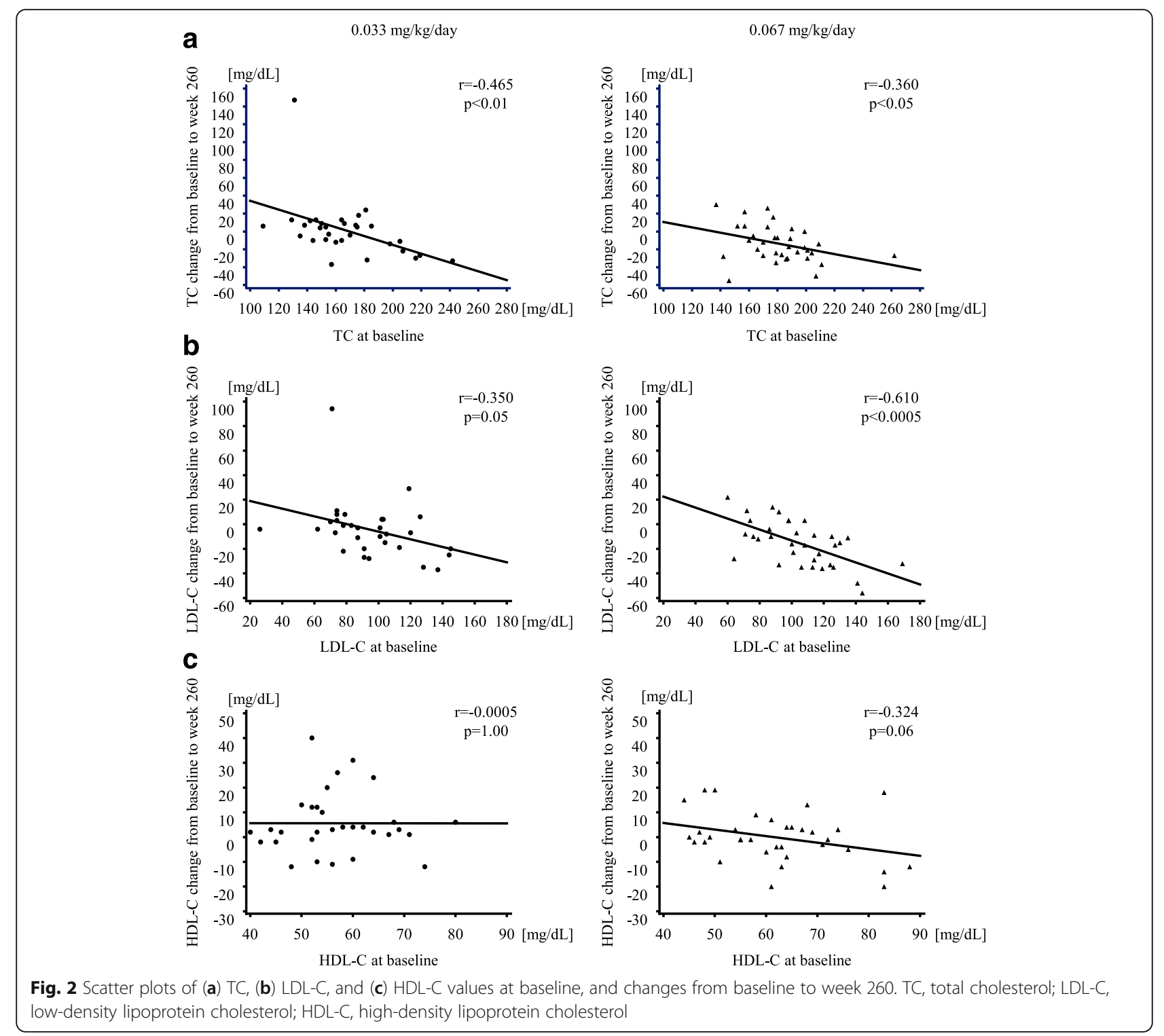

event, moderate in severity and assessed as possibly related to trial product. One patient from the no treatment group $/ 0.033 \mathrm{mg} / \mathrm{kg} /$ day withdrew after 212 weeks due to hyperinsulinemia. The event was mild in severity and assessed as possibly related to trial product.

\section{Discussion}

\section{Influence on lipid metabolism}

In the high dose group, significant decreases were found in TC and LDL-C levels 260 weeks after the start of GH therapy (Fig. 1). Mean TC decreased, especially in the high dose group, and this change was attributed to a decrease in LDL-C. The baseline status may have affected these decreases, because baseline mean values were significantly higher in male patients in the high dose group, leading to more significant decreases with the treatment, suggesting there might be a confounding factor (data not shown). TC and LDL-C levels were slightly lower in female patients. Since TC levels normally increase with puberty [15], the degree of decrease in TC observed may have been attenuated by pubertal hormonal changes. In the low dose group, a significant increase was observed in HDL-C levels, whereas no significant decreases were noted in TC and LDL-C levels. However, the clinical significance of this result currently remains unclear and awaits further investigation.

After 260 weeks, decreases in TC in the two dose groups and LDL-C in the high dose group correlated 


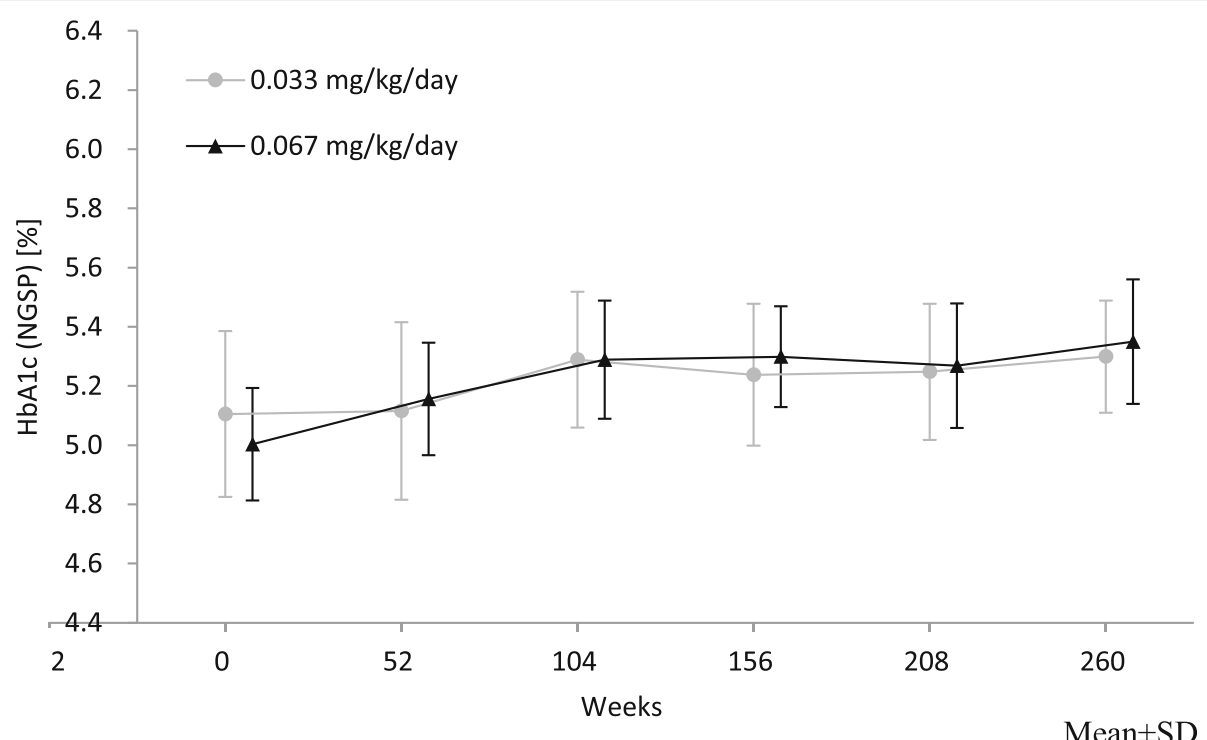

Fig. $3 \mathrm{HbA}_{1 c}$ (NGSP) during the study period. $\mathrm{HbA}_{1 c}$, glycated hemoglobin $\mathrm{A}_{1 c}$; NGSP, National Glycohemoglobin Standardization Program

with baseline values, indicating that the greater the baseline value, the greater the decrease observed after the treatment (Fig. 2). In both groups, a higher TC was more likely to decrease during GH therapy. This result is consistent with previous findings [16, 17], suggesting that long-term GH treatment has a favorable lowering effect on cholesterol, especially in those with higher cholesterol levels due to genetic and/or environmental backgrounds. No correlation was observed between HDL-C levels at the start of the study and changes after 260 weeks of GH therapy. One patient had markedly higher TC and LDL-C levels than those of the other patients. This patient had a history of IgA nephropathy, which may have elevated TC and LDLC levels [18].

\section{Influence on glucose metabolism}

Post-OGTT insulin levels increased with each year of long-term GH treatment, particularly in the high dose group (Fig. 5). It is possible that the increase in HOMA-IR levels in the final year of GH therapy was a result of patients transitioning into puberty. Overall, $35 \%$ of patients in the low dose group and $37.5 \%$ of patients in the high dose group entered puberty during the study period. The increase in post-OGTT insulin levels is consistent with previous findings in which patients became relatively resistant to insulin after the start of GH therapy [19]. Fasting insulin levels have been shown to increase with age [15]; therefore, the results obtained in this study reflected physiological changes. Previous studies demonstrated that bioactive IGF-I levels increased through decreases in IGF-binding protein in the presence of hyperinsulinemia [20]. Furthermore, an increase in insulin levels has been suggested to promote growth [21].

After long-term GH therapy (260 weeks), the HOMA-IR (Table 3) and insulinogenic index increased. However, no significant differences were observed between the two dose groups, indicating no dose dependency. These results also demonstrated that the $\mathrm{GH}$ dose of $0.033 \mathrm{mg} / \mathrm{kg} /$ day was already greater relative to $\mathrm{GH}$ secreted from the pituitary in normal physiology. Patients with a HOMA-IR of 2.5 or higher are regarded as being resistant to insulin $[13,14]$, and $25 \%$ of patients in this study (low dose group: 5 out of 20 patients, high dose group: 4 out of 16 patients) exhibited insulin resistance after 260 weeks of $\mathrm{GH}$ therapy. These results suggest that, although the dose may be increased in accordance with the responsiveness of individual patients to $\mathrm{GH}$ therapy, dose elevations within these limits do not influence glucose tolerance.

No correlations were observed between the HOMA-IR and BMI SDS or between the $\mathrm{HbA}_{1 \mathrm{c}}$ and BMI SDS after 260 weeks of $\mathrm{GH}$ therapy. The mean BMI SDS in this study was below 0 SD during the study period and our patients did not include those with a very high/low BMI. A larger number of patients need to be analyzed in future studies in order to more clearly elucidate the relationship between BMI and glucose metabolism in GH-treated SGA. 


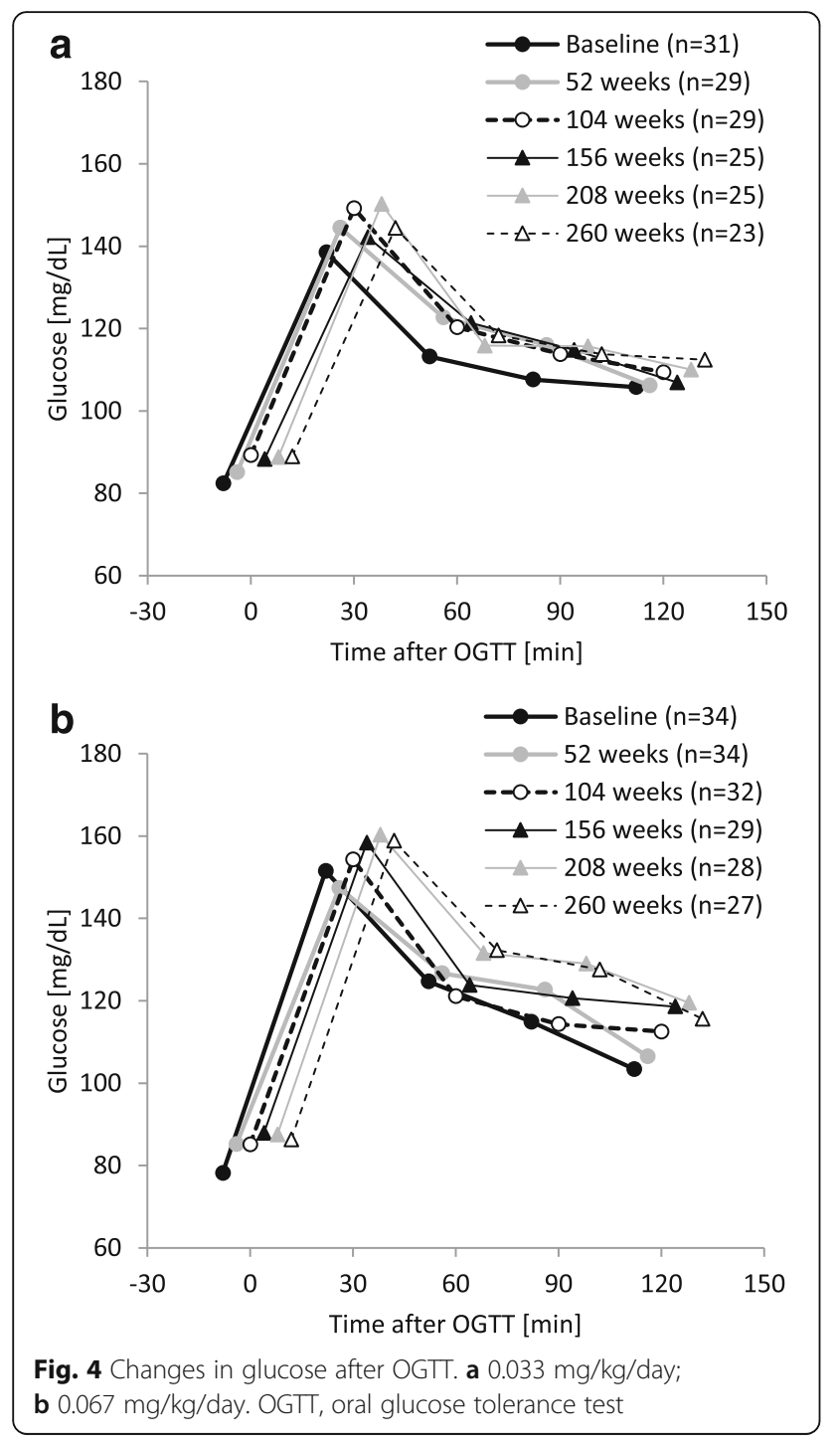

\section{Conclusions}

This study investigated the effect of long term continuous GH treatment in children born SGA on lipid and glucose metabolism. In the high dose group, TC and LDL-C levels decreased significantly over time during the GH therapy. Baseline values correlated with the reductions after 260 weeks in both groups for TC and in the high dose group for LDL-C. This result suggests that the long-term GH treatment used had favorable lowering effects on cholesterol, especially in those with higher cholesterol levels. $\mathrm{HbA}_{1 \mathrm{c}}$ values slightly increased, and post-OGTT insulin levels increased with each year of $\mathrm{GH}$ treatment; however, no marked changes were noted in the blood glucose response to OGTT during the 260 weeks of treatment. In healthy adolescents, decreased insulin sensitivity observed during puberty is compensated for by an
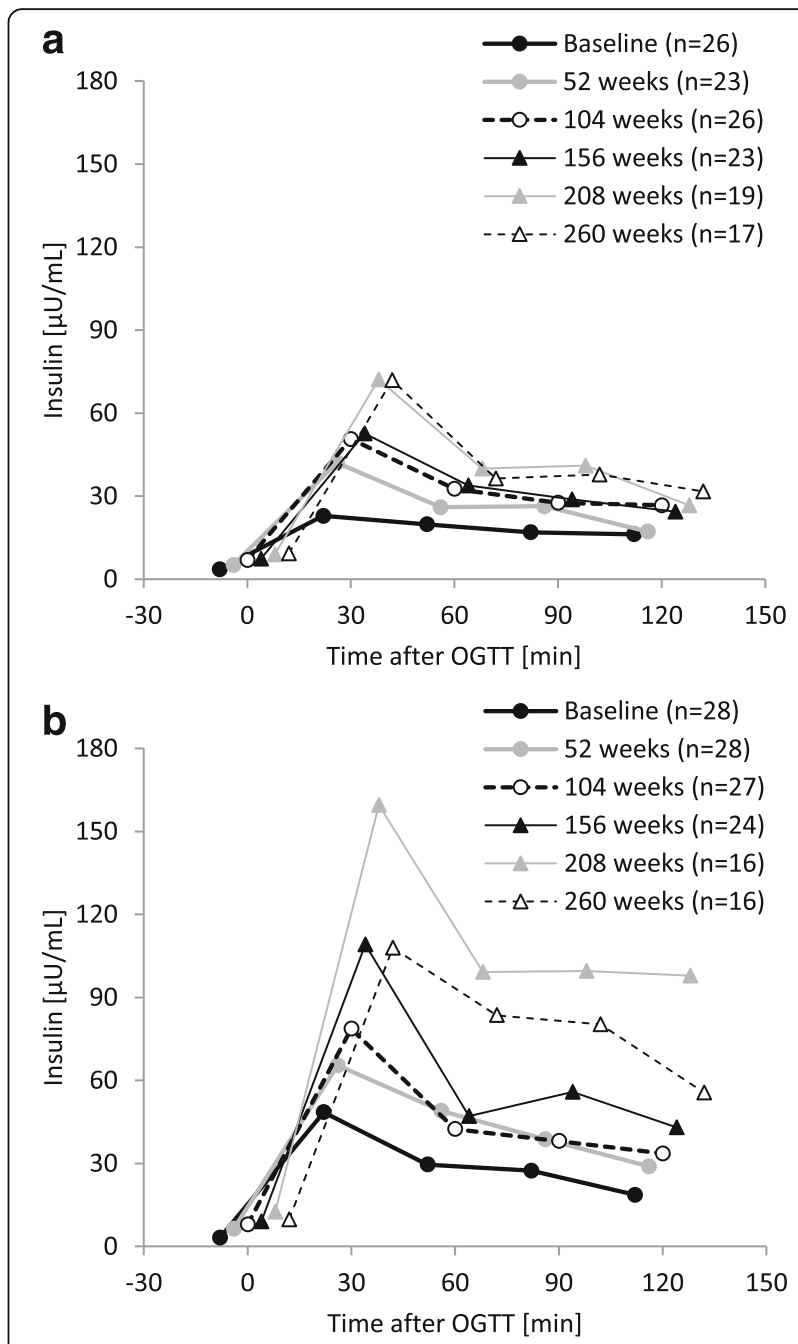

Fig. 5 Changes in insulin after OGTT. a 0.033 mg/kg/day; b $0.067 \mathrm{mg} / \mathrm{kg} /$ day. OGT, oral glucose tolerance test

increase in insulin secretion, hence the increase in HOMA-IR levels observed in the final year of GH therapy may have been a result of patients transitioning into puberty.

The results of this study suggest long-term continuous GH treatment for children born SGA may have potentially beneficial effects on several parameters of lipid metabolism and does not have an adverse effect on glucose metabolism.

Table 3 HOMA-IR [Mean \pm SD]

\begin{tabular}{lcc}
\hline & $\begin{array}{l}0.033 \mathrm{mg} / \mathrm{kg} / \mathrm{day} \\
\mathrm{n}=20\end{array}$ & $\begin{array}{l}0.067 \mathrm{mg} / \mathrm{kg} / \mathrm{day} \\
\mathrm{n}=16\end{array}$ \\
\hline Baseline & $0.720 \pm 0.465$ & $0.646 \pm 0.498$ \\
260 weeks & $2.154 \pm 1.682$ & $1.895 \pm 1.197$ \\
\hline $\begin{array}{l}\text { SD standard deviation, HOMA-IR homeostatic model assessment as an index of } \\
\text { insulin resistance }\end{array}$ &
\end{tabular}




\section{Appendix}

Institutional review boards providing approval for the present study

Pharmaceuticals Clinical Study Institutional Review

Board, Asahikawa Medical College Hospital

Institutional Review Board, Kushiro Red Cross Hospital

Pharmaceuticals Clinical Study Institutional Review

Board, Hirosaki University School of Medicine Hospital

Institutional Review Board, Igarashi Children's Clinic

Institutional Review Board, Niigata City General Hospital

Pharmaceuticals Medical Devices Clinical Study

Institutional Review Board, Niigata University Medical

and Dental Hospital

Clinical Study Institutional Review Board, Gunma

University Hospital

Institutional Review Board, Dokkyo University School of Medicine Hospital

Pharmaceuticals Entrusted Clinical study Institutional

Review Board

Institutional Review Board, Saitama Medical School

Hospital

Institutional Review Board, National Center for Child

Health and Development

Institutional Review Board, Toranomon Hospital

Institutional Review Board, Keio University Hospital

Institutional Review Board, Tokyo Metropolitan Ohtsuka

Hospital

Institutional Review Board, Tokyo Metropolitan Kiyose

Children's Hospital

Pharmaceuticals Clinical Study Institutional Review

Board, University of Yamanashi Hospital

Institutional Review Board, National Hospital

Organization Nagano Hospital

Institutional Review Board, Juntendo Shizuoka Hospital

Institutional Review Board, Hamamatsu Medical School

Hospital

Institutional Review Board, Fujita Health University

Hospital

Institutional Review Board, Toyohashi Municipal

Hospital

Pharmaceuticals Clinical Study Institutional Review

Board, Nagoya City University Hospital

Institutional Review Board, Japanese Red Cross Nagoya

First Hospital

Institutional Review Board, West Medical Center

Jouhoku Municipal Hospital, City of Nagoya

Pharmaceuticals Entrusted Clinical Study Institutional

Review Board, Osaka University Hospital

Institutional Review Board, Osaka Medical Center and

Research Institute for Maternal and Child Health

Entrusted Clinical Study Institutional Review Board,

Osaka City General Hospital

Institutional Review Board, Kansai Medical University

Kori Hospital
Institutional Review Board, Osaka Prefecture Medical

Association

Pharmaceuticals Clinical Study Institutional Review

Board, Kagawa University Hospital

Institutional Review Board, Okayama University

Hospital

Institutional Review Board, Hiroshima Red Cross

Hospital \& Atomicbomb Survivors Hospital

Institutional Review Board, Hiroshima Prefectural

Hospital

Institutional Review Board, Tottori University Hospital

Institutional Review Board, Kumamoto University

Hospital

Institutional Review Board, Kumamoto University

Hospital

Institutional Review Board, Miyazaki University Hospital

Institutional Review Board, Ichinomiya Municipal

Hospital

Pharmaceuticals Clinical Study Institutional Review

Board, Fukui University Hospital

Institutional Review Board, Kyushu Kosei Nenkin

Hospital

Clinical Study Institutional Review Board, Fukuoka

University Hospital

Institutional Review Board, Tohoku University Hospital

Institutional Review Board, Tendo Municipal Hospital

Institutional Review Board, Osaka Kosei Nenkin

Hospital

\section{Abbreviations}

BMI: Body mass index; GH: Growth hormone; $\mathrm{HbA}_{1}$ : Glycated hemoglobin $\mathrm{A}_{1 c}$; HDL-C: High-density lipoprotein cholesterol; HOMA-IR: Homeostatic model assessment as an index of insulin resistance; IGF-I: Insulin-like growth factor-1; LDL-C: Low-density lipoprotein cholesterol; NGSP: National Glycohemoglobin Standardization Program; OGTT: Oral glucose tolerance test; SDS: Standard deviation score; SGA: Small for gestational age; TC: Total cholesterol

\section{Acknowledgments}

The authors would like to thank our patients and their families and all physicians and study sites who participated in this study.

\section{Funding}

This study was funded by Novo Nordisk Pharma Ltd and Novo Nordisk A/S, Bagsværd, Denmark.

\section{Availability of data and materials}

Some data are available on Japanese government website (in Japanese), available at: http://www.pmda.go.jp/PmdaSearch/iyakuSearch/.

\section{Authors' contributions}

$\mathrm{RH}, \mathrm{T}$, and SY contributed to the study coordination, treatment of patients, acquisition and interpretation of data, advised and reviewed the draft of the manuscript, and helped to revise the manuscript. YO coordinated the study, interpreted data, advised and reviewed the draft of the manuscript, and helped to revise the manuscript. HN wrote the first draft of the manuscript and subsequent revisions. All authors read and approved the final manuscript.

\section{Competing interests}

$\mathrm{RH}, \Pi$, and SY have participated in data collection for patient registries, with research support from Novo Nordisk Pharma Ltd. RH and SY have received research grant support from Novo Nordisk Pharma Ltd. HN and YO are employees of Novo Nordisk Pharma Ltd. 


\section{Consent for publication}

Not applicable.

\section{Ethics approval and consent to participate}

This study was performed in accordance with the Declaration of Helsinki and The Ministerial Ordinance on Good Clinical Practice (GCP) for Drugs. Written informed consent was obtained from the patients themselves or their parents/legal guardians. The study protocol was approved by the Institutional Review Boards listed in the Appendix.

\section{Author details}

'Division of Endocrinology and Metabolism, National Center for Child Health and Development, 2-10-1 Okura, Setagaya-ku, Tokyo 157-8535, Japan.

${ }^{2}$ Tanaka Growth Clinic, 2-36-7 Yoga, Setagaya-ku, Tokyo 158-0097, Japan.

${ }^{3}$ CMR Development Division, Novo Nordisk Pharma Ltd., 2-1-1 Marunouchi, Chiyoda-ku, Tokyo 100-0005, Japan. ${ }^{4}$ Department of Medical Subspecialties, National Center for Child Health and Development, 2-10-1 Okura, Setagaya-ku, Tokyo 157-8535, Japan.

Received: 15 December 2015 Accepted: 19 September 2016 Published online: 26 October 2016

\section{References}

1. Tanaka T, Yokoya S, Nishi Y, Hasegawa Y, Yorifuji T, Fujieda K, et al. Management of short children born small for gestational age. J Jpn Pediatr Soc. 2007:111:641-6.

2. Karlberg J, Albertsson-Wikland K. Growth in full-term small-for-gestationalage infants: from birth to final height. Pediatr Res. 1995;38:733-9.

3. Hokken-Koelega AC, De Ridder MA, Lemmen RJ, Den Hartog H, De Muinck Keizer-Schrama SM, Drop SL. Children born small for gestational age: do they catch up? Pediatr Res. 1995;38:267-71.

4. Itabashi K, Mishna J, Tada H, Sakurai M, Nanri Y, Hirohata Y. Longitudinal follow-up of height up to five years of age in infants born preterm small for gestational age; comparison to full-term small for gestational age infants. Early Hum Dev. 2007:83:327-33.

5. Barker DJ, Hales CN, Fall CH, Osmond C, Phipps K, Clark PM. Type 2 (non-insulin-dependent) diabetes mellitus, hypertension and hyperlipidaemia (syndrome X): relation to reduced fetal growth. Diabetologia. 1993;36:62-7.

6. Ong KK, Petry CJ, Emmett PM, Sandhu MS, Kiess W, Hales CN, et al. Insulin sensitivity and secretion in normal children related to size at birth, postnatal growth, and plasma insulin-like growth factor-I levels. Diabetologia. 2004;47:1064-70.

7. Soto N, Bazaes RA, Peña V, Salazar T, Avila A, Iñiguez G, et al. Insulin sensitivity and secretion are related to catch-up growth in small-forgestational-age infants at age 1 year: results from a prospective cohort. J Clin Endocrinol Metab. 2003;88:3645-50.

8. Mericq V, Ong KK, Bazaes R, Pena V, Avila A, Salazar T, et al. Longitudina changes in insulin sensitivity and secretion from birth to age three years in small- and appropriate-for-gestational age children. Diabetologia. 2005;48:2609-14

9. Lebl J, Lebenthal Y, Kolouskova S, Steensberg A, Jons K, Kappelgaard AM, et al. Metabolic impact of growth hormone treatment in short children born small for gestational age. Horm Res Paediatr. 2011;76:254-61.

10. van Dijk M, Bannink EM, van Pareren YK, Mulder PG, Hokken-Koelega AC Risk factors for diabetes mellitus type 2 and metabolic syndrome are comparable for previously growth hormone-treated young adults born small for gestational age (sga) and untreated short SGA controls. J Clin Endocrinol Metab. 2007:92:16-5.

11. Tanaka T, Yokoya S, Seino Y, Togari H, Mishina J, Kappelgaard AM, Fujieda K. Long-term efficacy and safety of two doses of growth hormone in short Japanese children born small for gestational age. Horm Res Paediatr. 2011;76:411-8

12. Kappelgaard AM, Kiyomi F, Horikawa R, Yokoya S, Tanaka T. The impact of long-term growth hormone treatment on metabolic parameters in Japanese patients with short stature born small for gestational age. Horm Res Paediatr. 2014,81:272-9.

13. Committee of the Japan Diabetes Society on the Diagnostic Criteria of Diabetes Mellitus, Seino Y, Nanjo K, Tajima N, Kadowaki T, Kashiwagi A, et al. Report of the committee on the classification and diagnostic criteria of diabetes mellitus. J Diabetes Investig. 2010;1:212-28.
14. Japan Diabetes Society. Treatment guide for diabetes 2014-2015. Tokyo: Bunkodo; 2014.

15. Matsui I, Nambu S, Baba S. Evaluation of fasting serum insulin levels among Japanese school-age children. J Nutr Sci Vitaminol. 1998:44:819-28.

16. Abs R, Feldt-Rasmussen U, Mattsson AF, Monson JP, Bengtsson BA, Góth MI, et al. Determinants of cardiovascular risk in 2589 hypopituitary $\mathrm{GH}$-deficient adults - a KIMS database analysis. Eur J Endocrinol. 2006;155:79-90.

17. Monson JP, Jönsson P, Koltowska-Häggström M, Kourides I. Growth hormone $(\mathrm{GH})$ replacement decreases serum total and LDL-cholesterol in hypopituitary patients on maintenance HMG CoA reductase inhibitor (statin) therapy. Clin Endocrinol (Oxf). 2007;67:623-8.

18. Asami T, Hayakawa H, Ohkawa K, Uchiyama M. Hypercholesterolemia and glomerular diseases in urinary screening of school children. Pediatr Nephrol. 1999;13:125-8

19. Sas T, Mulder P, Aanstoot HJ, Houdijk M, Jansen M, Reeser M, HokkenKoelega A. Carbohydrate metabolism during long-term growth hormone treatment in children with short stature born small for gestational age. Clin Endocrinol (Oxf). 2001;54:243-51.

20. Yasunaga T, Furukawa S, Katsumata N, Horikawa R, Tanaka T, Tanae A, Hibi I. Nutrition related hormonal changes in obese children. Endocr J. 1998:45:221-7.

21. Messina JL. Insulin as a growth-promoting hormone. In: Handbook of physiology. Supplement 24. The Endocrine System, Hormonal Control of Growth. Hoboken: Wiley; 2011. p. 783-811.

\section{Submit your next manuscript to BioMed Central and we will help you at every step:}

- We accept pre-submission inquiries

- Our selector tool helps you to find the most relevant journal

- We provide round the clock customer support

- Convenient online submission

- Thorough peer review

- Inclusion in PubMed and all major indexing services

- Maximum visibility for your research

Submit your manuscript at www.biomedcentral.com/submit
Biomed Central 